\title{
Macrostructural changes of polymer replicated open cell cordierite based foams upon sintering
}

\author{
M. J. Matos, S. Dias and F. A. Costa Oliveira*
}

\begin{abstract}
The goal of this work was to clarify the macrostructural changes that take place upon sintering of open cell cordierite based foams. A methodology, based on optical image analysis, was developed to assess the structure of open-cell foams, which allowed evaluating the macrostructure of both cordierite based foams obtained by the replication process and their polymeric templates. The parameters used to describe the structures were the size of the cell and the window, the window shape factor, the strut thickness and the volume fraction of the material. The experimental evidence gathered opened the way to understand the physical/chemical transformations involved in the polymer burnout and the ceramic sintering processes, as well as their influence on the ceramic final structure. The observed trends provide guidance for tailoring 'replicated' cordierite based foams, in view of the required application.
\end{abstract}

Keywords: Replication process, Cellular ceramics, Thermal properties, Cordierite, Substrates

\section{Introduction}

Open cell ceramic foams are being increasingly applied for fluid transport at high temperatures, owing to their properties, namely the low thermal conductivity, high refractoriness, high permeability, high stiffness, low weight and excellent corrosion and thermal shock resistances. Examples of major applications include light structure plates, thermal insulating materials, fire protection materials, gas combustion burners, hot gas and liquid metal filters, biomedical implants and catalyst substrates. ${ }^{1}$ In practice, however, ceramic foams are very brittle and their mechanical properties are closely related to the type and size of the cells, as well as to the relative density of the structure. Hence, it is important to understand the relationship between the structure and the mechanical behaviour, being aware of the key parameters involved in producing structures which may provide desired mechanical properties; relevant key parameters are the cell shape and size distribution, the proportion of open and closed cell windows, the length and thickness of the struts.

Although considerable research work has been devoted towards characterising the structure of open cell foams, no standard experimental technique has yet been established. Current techniques usually rely on the subjective visual examination of the material surface. Ceramic foams are often summarily described by the mean pore diameter, which is compared with the

Department of Materials and Production Technologies, Instituto Nacional de Engenharia, Tecnologia e Inovação, I.P. (INETI), Estrada do Paço do Lumiar, 1649-038 Lisboa, Portugal

*Corresponding author, email fernando.oliveira@ineti.pt nominal pore size, provided by the manufacturer. ${ }^{2}$ For many years, the cellular structures were simply characterised by the size of the cells, defined by the number of pores per inch (PPI method). And more recently, the data concerning the pore and window size distributions, determined by the chord intercept length method, are reported, ${ }^{3}$ although without mentioning any scatter. Under certain assumptions, correction factors are used in order to account for the random orientation of the struts in the three dimensional (3D) structures. ${ }^{4-7}$

More recently, Olurin et $a l^{8}$ and Maire et $a l^{9}$ reported the potential of using microcomputer tomography in characterising the $3 \mathrm{D}$ structural morphometric parameters (e.g. volume density) of closed cell aluminium foams and cellular ceramics, respectively. However, the procedure for analysis is far from being established.

Mullens et al. ${ }^{10}$ have also reviewed the main characterisation methods for resolving the morphology of ceramic foams. The volumic description of these structures requires several parameters such as cell size distribution and cell morphology, cell window opening, strut thickness and its distribution, strut shape and morphology (e.g. hollow or dense), porosity, interconnectivity, type of porosity (open versus closed), relative density, surface/volume ratio, degree of anisotropy. Although many characterisation techniques, namely the PPI method, the Visiocell method, image analysis, capillary flow porosimetry, microcomputer tomography and mercury porosimetry, have proven their merit, their potential in assessing the parameters that describe the shape, isotropy and interconnectivity of single cells in cellular materials, is still to be explored. 
In general, 3D images are regarded to be more appropriate for quantifying the morphology than 2D ones. However, there are a few exceptions. For instance, the quantification of the size of the windows connecting the pores is easier to perform using image analysis of micrographs than using tomography. This comes from the fact that both optical and electron microscopy can image the structure over a large depth, which makes it easier to measure more precisely the size of the interconnecting windows.

It is worth noting that no single analytical technique can provide a complete and accurate description of ceramic foam structures. ${ }^{10}$ Therefore, a need exists for developing a standard procedure for analysing cellular structures, which would combine the techniques to be used, in function of the information provided, in order to gather an overall picture of the 3D cellular structure.

The present paper provides a contribution towards assessing the macrostructure of open cell foams, and evaluating the correlations between the macrostructural features of cordierite based foams fabricated by the replication process and the polymeric foams used as templates, through the use of image analysis.

The 'replication' process is the most versatile and widely used method for producing cellular ceramic materials. It is based on the impregnation of flexible open-cell polymer foams with slurries of ceramic particles, ${ }^{11}$ followed by the polymer burnout and the ceramic sintering, in order to yield a replica of the original foam. Slurries are made up of ceramic particles, water and additives, which can provide handling strength, as well as preventing the collapse of the structure during the polymer removal. The ceramic foam structure is controlled by the structure of the template (such as porosity and pore size distribution), the amount of slurry that remains in the template after impregnation and the shrinkage of the material during the ceramic sintering process.

The relationships between the ceramic and the polymeric structures, ${ }^{12,13}$ together with the understanding of the physicochemical mechanisms inherent to the fabrication process, provided guidance for tailoring 'replicated' cordierite based foams.

\section{Experimental}

\section{Foam preparation}

The cordierite based ceramic foams were fabricated by the replication method, which was described in more detail elsewhere (including a thorough characterisation of the rheological behaviour of the ceramic suspensions). ${ }^{12}$ Briefly, optimised aqueous slurries with a solid content of 40 vol.- $\%$ prepared from a commercial powder mixture of materials (ball clays, talc, alumina and silica) that form cordierite upon firing (from Rauschert Portuguesa Ltd., Carcavelos, Portugal, characterised by a specific surface area $11 \mathrm{~m}^{2} \mathrm{~g}^{-1}$, average particle size $4.5 \mu \mathrm{m}$ and true density $2.91 \mathrm{~g} \mathrm{~cm}^{-3}$ ), were used to impregnate open cell polyurethane (PU) foams (grades 20DB and 22SB4 from Flexipol - Espumas Sintéticas S. A., S. João da Madeira, Portugal). PU foams possess adequate resiliency, hydrophobic behaviour, ability to be uniformly covered and low temperature of volatilisation without yielding noxious byproducts, which make them suitable to produce fine $(<1 \mathrm{~mm}$ cell size $)$ ceramic foams.

Samples of PU foams were dipped into the ceramic slurry, compressed to fill the void space, and then passed through preset rotating rollers to remove the excess of slurry. Following an optimisation stage, the span between rollers was set to result in a foam compression of $80 \%$ of the initial thickness. After drying at $100^{\circ} \mathrm{C}$ overnight, the sponges were heated at $1 \mathrm{~K} \mathrm{~min}^{-1}$ to $500^{\circ} \mathrm{C}$ for $1 \mathrm{~h}$, in air, and subsequently sintered at $1300^{\circ} \mathrm{C}$ in an industrial furnace using natural gas as fuel. The burning schedule of the polymer foam ${ }^{11}$ and the material itself was optimised under the basis of differential thermal analysis (DTA) and thermogravimetry (TG) measurements. These were performed on a TG-DTA apparatus (Setaram Labsys ${ }^{\mathrm{TM}}$, France) using samples placed in an alumina crucible which was heated in an atmosphere of flowing $\left(\approx 1 \mathrm{~L} \mathrm{~h}^{-1}\right)$ dry air. The temperature signal of the DTA instrument was checked with a Ni standard and powdered $\alpha$-alumina was used as a reference material. The heating rate was set at $5 \mathrm{~K} \mathrm{~min}^{-1}$ (in the case of the polymer foams) and $20 \mathrm{~K} \mathrm{~min}^{-1}$ (in the case of the ceramic material, to permit the observation of the crystallisation peak of cordierite) followed by natural cooling to the room temperature. The evolution of the phases formed at the different temperatures was evaluated by XRD analysis.

\section{Image analysis routine}

The key macrostructural features of both polymeric and ceramic foams were characterised by image analysis of representative foam's sections. ${ }^{14}$ Samples of two grades of PU foams, named as 20DB (PU) and 22SB4 (PU), were cut, with a sharp blade, into very thin slices $(\sim 0.1 \mathrm{~mm})$, which were used to acquire optical images using a Zeiss Axiovert 200 M MAT optical microscope (Carl Zeiss Mikroskopie, Jena, Germany). Samples of in-house developed polymer-replicated foams, named as $20 \mathrm{DB}$ and 22SB4, were used, as sintered, to acquire optical images. These samples were also observed and imaged using a Philips XL30 FEG SEM and backscattered electron beams at 1 to $10 \mathrm{kV}$.

Optical images were examined to determine the cell size $D$ (cell equatorial diameter), ${ }^{15}$ the window size $w$ (major axis of window) ${ }^{15}$ the window shape factor a.r. ('aspect ratio', which represents the ratio between the length of the major axis and its perpendicular), the strut thickness $l$ (strut transverse length), and the material volume fraction $V_{V}$ (proportion of material in the structure, measured by chord intercept lengths). The volume fraction is an indicator of the porosity $P$, given by $P=1-V_{V}$.

Data gathered corresponds to the measurement of 20 grey images for each type of foam, acquired with a resolution of $1300 \times 1030$ pixel at a magnification of $50 \mathrm{X}$. Volume fraction was determined by scanning the images with three lines spaced by about $540 \mu \mathrm{m}$ and $2700 \mu \mathrm{m}$ length, which corresponds to scanning each image with a line of $8100 \mu \mathrm{m}$ length.

Measurements involved only the features under focus, whose number differed from image to image. The averaged data corresponds to measuring a total of about 60 cell sizes $(D), 40$ window sizes $(w), 40$ aspect ratios (a.r.), 40 strut thicknesses $(l)$ and 80 volume fractions $(V v)$. Such a limited set of data is related to the difficulties in obtaining the cell equatorial diameters. 

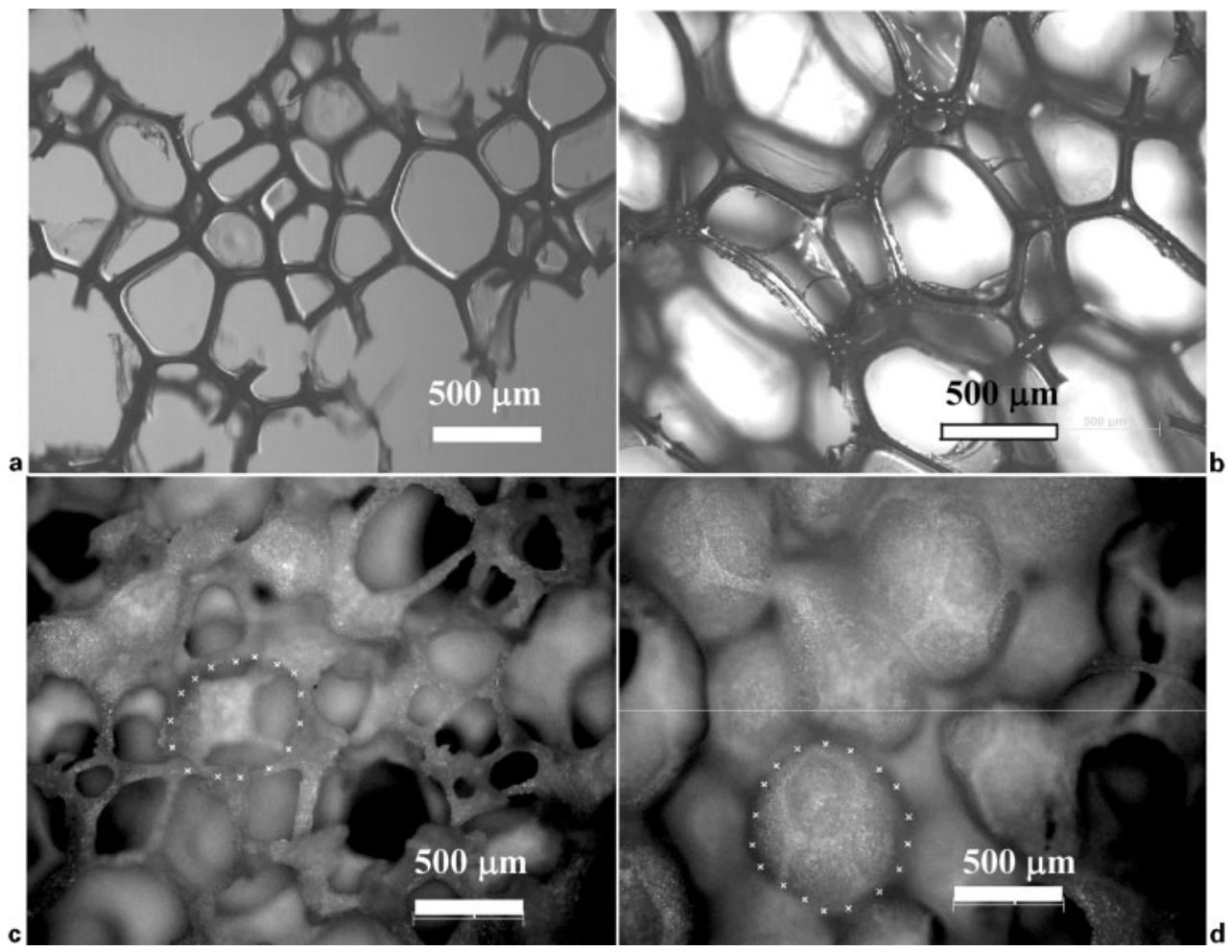

a PU(20DB); $b$ PU(22SB4); c CF(20DB); $d$ CF(22SB4)

1 Optical images of foam structures

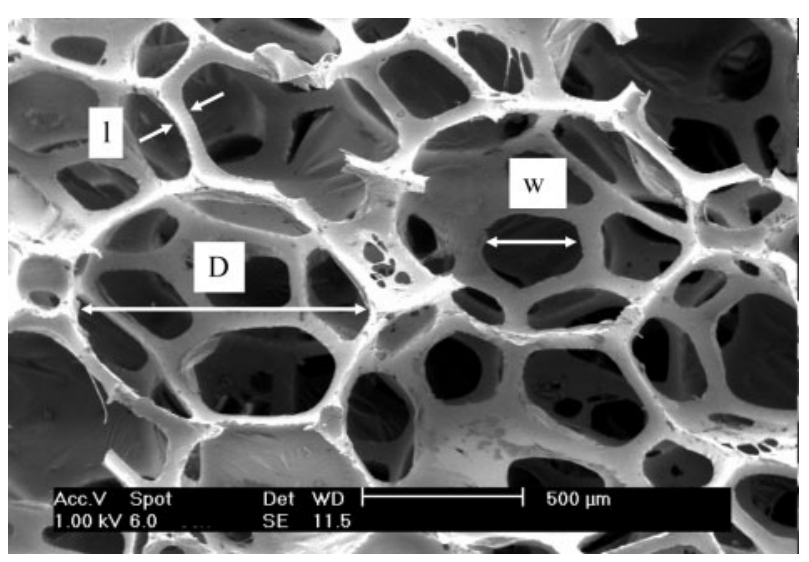

2 Image (SEM) of polyurethane open cell foams illustrating measured macrostructural parameters: $D$ (cell size), w (window size) and I (strut thickness)

The cells and windows values were grouped in classes of size and plotted as numberweighted distributions (number $\%)$.

\section{Results}

\section{Image analysis}

Typical optical images of both the PU foams ( $a$ and $b$ ) and the resulting cordierite based foams $(c$ and $d$ ) are given in Fig 1. The parameters measured on the images are shown in Fig. 2. Data are summarised in Table 1. The cell and window size distributions are compared in Fig. 3.

The data collected correspond to a number of measurements (sample size) which enables accepting the averaged values at the $5 \%$ confidence level, with the exception of PU parameter $\boldsymbol{w}$, which would require a minimum of 75 and 95 measurements, respectively for 20DB and 22SB4, in order to fall in the same confidence interval.

As shown in Fig. 1, some cells present the windows closed with a thin membrane, which is particularly evident in the ceramic foams. As pointed out elsewhere, ${ }^{12}$ the foams developed are of the semiclosed cell type. ${ }^{16}$ Attention is drawn to the fact that some of the cells contain closed windows rather than being closed (Fig. 4).

In what respects the structure, data in Table 1 and plots in Fig. 3 show clearly that the 'replicated' ceramic foams $(\mathrm{CF})$ reflect the internal architecture of the respective templates, and point out the following main morphological differences:

\section{Polymers:}

- The cell size distribution of 20DB is finer and wider than that of 22SB4;

- The window size distribution of 20DB is finer and possesses a higher fraction of smaller windows than that of 22SB4;

\section{Table 1 Summary of the macrostrutural parameters data obtained on the foam sections (mean \pm standard deviation)}

\begin{tabular}{|c|c|c|c|c|c|}
\hline FOAMS & Cell size $\bar{D}, \mu \mathrm{m}$ & Window size $\bar{w}, \mu \mathrm{m}$ & Strut thickness $\bar{l}, \mu \mathrm{m}$ & Window aspect ratio ar & Volume fraction $V_{V}$ \\
\hline \multicolumn{6}{|c|}{ Polymeric } \\
\hline 20DB & $687 \pm 186$ & $326 \pm 140$ & $53 \pm 3$ & $1.31 \pm 0.24$ & $0.31 \pm 0.07$ \\
\hline $\begin{array}{l}\text { 22SB4 } \\
\text { Ceramic }\end{array}$ & $952 \pm 148$ & $473 \pm 230$ & $67 \pm 4$ & $1.57 \pm 0.19$ & $0.27 \pm 0.04$ \\
\hline 20DB & $520 \pm 130$ & $376 \pm 69$ & $60 \pm 10$ & $1 \cdot 15 \pm 0 \cdot 15$ & $0.25 \pm 0.07$ \\
\hline 22SB4 & $782 \pm 150$ & $589 \pm 163$ & $63 \pm 7$ & $1 \cdot 30 \pm 0.12$ & $0.30 \pm 0.05$ \\
\hline
\end{tabular}


(a)

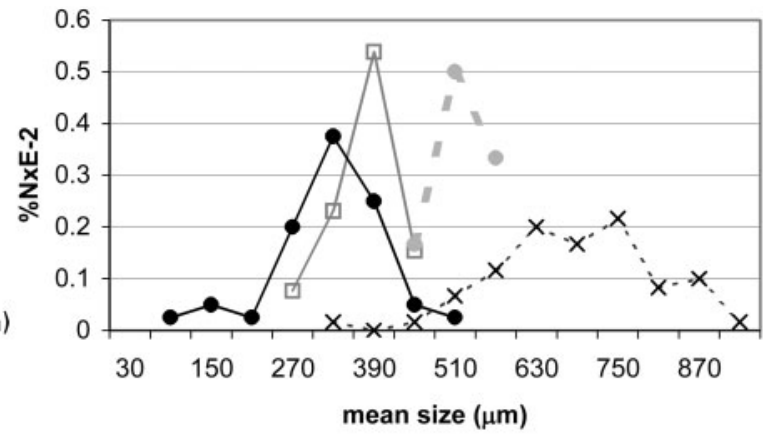

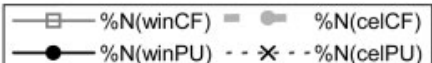

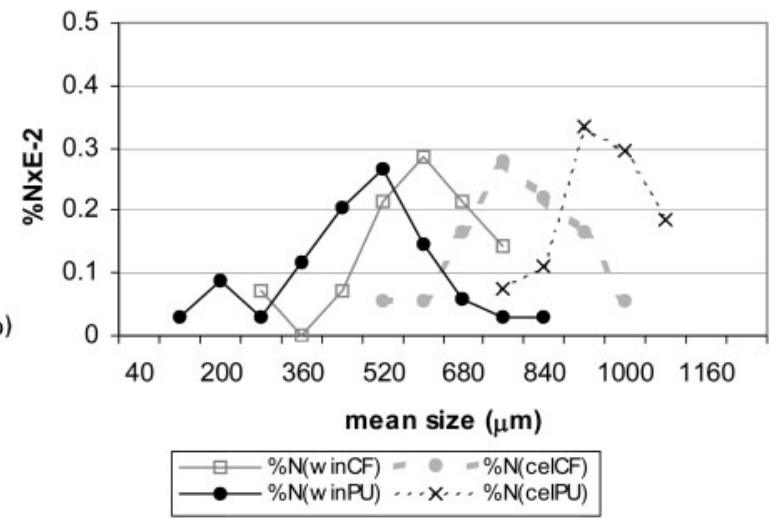

a 20DB; $b$ 22SB4

3 Cell and window size distributions (number \%) of ceramic foams and respective polymeric templates

- The window elliptical shape in 22SB4 is more accentuated than that in 20DB.

\section{Ceramics versus Polymers:}

- The average cell sizes of the ceramic foams are smaller than those of the respective templates;

- In case of 20DB foams, the size distribution of the ceramic cells is narrower than that of the polymer cells, and is contained in this one: neither the smaller cell sizes nor the larger ones of the polymers were observed in the ceramic foams (Fig. 3);

- The average window sizes of the ceramic foams are coarser than those of the respective templates;

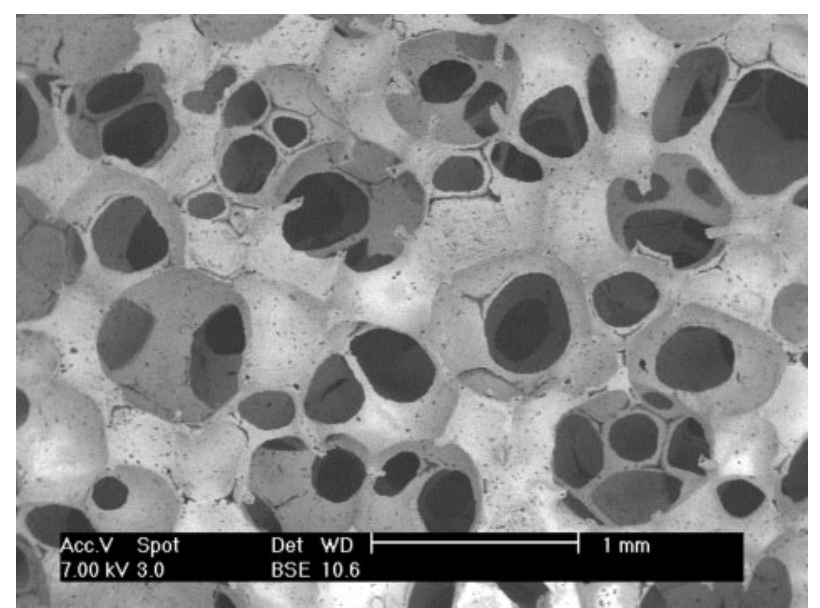

4 Image (SEM) of a foam showing cells with closed windows

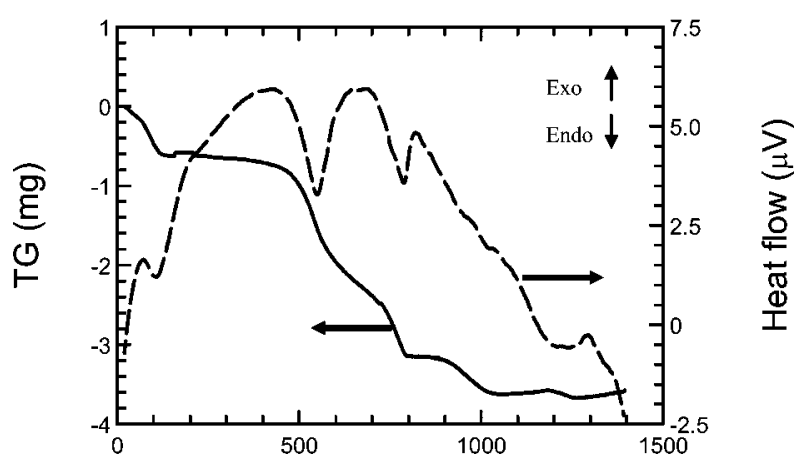

$\mathrm{T}\left({ }^{\circ} \mathrm{C}\right)$

5 Plots of DTA/TG curves collected for raw material heated at $20 \mathrm{~K} \mathrm{~min}^{-1}$ up to $1400^{\circ} \mathrm{C}$ in flowing dry air

- In both ceramic foams, the window sizes are distributed in narrower ranges than those of their respective templates (Fig. 3);

- The ceramic cell windows are more 'round' than those of their respective templates.

It was also observed that both PU and CF consist of an irregular packing of cells with different shapes and sizes. Most of the cells possess faces with five edges and a number of closed windows. In the case of PU(20DB) foam, cell windows with 4 edges and cells with 10 faces predominated whereas predominance of windows with 5 edges and cells with 12 faces was observed in the case of PU(22SB4) foam. In respect of the shape, the 'polyhedral' polymeric cells turned into 'spherical' ceramic cells.

\section{Burnout of the polymeric templates}

Previous studies revealed that the PU foams began decomposing at $\sim 250^{\circ} \mathrm{C}$, started melting at $\sim 300^{\circ} \mathrm{C}^{12}$ and completed decomposition at $\sim 450^{\circ} \mathrm{C}$. In this temperature range, the shrinkage of the ceramic particles is extremely low and the collapse of the ceramic web may occur, and is promoted by the pressure of the gases liberated during the polymer degradation, as temperature rises. An adequate control of the heating schedules is necessary to avoid collapse. Chemical analysis of the exhaust gases, performed according to ISO NP 10 396, revealed that the burnout of the polymer produced mainly $\mathrm{CO}_{2}$, together with traces of $\mathrm{SO}_{2}\left(<7 \mathrm{mg} \mathrm{m}^{-3}\right)$, $\mathrm{CO}\left(<65 \mathrm{mg} \mathrm{m}^{-3}\right)$, VOC's $\left(<10 \mathrm{mg} \mathrm{m}^{-3}\right)$ and $\mathrm{NO}_{\mathrm{x}}$ $\left(<2 \mathrm{mg} \mathrm{m}^{-3}\right)$.

\section{Cordierite formation}

The physicochemical reactions that occur during the conversion of the green into sintered foam depend on the temperature, the time and atmosphere during the firing, the composition of the raw materials and the volumic distribution of the cells (also referred to as pores).

The sequence of the chemical reactions that take place during firing, as depicted in typical DTA and TG curves, is shown in Fig. $5 .{ }^{17}$ Briefly, a first endothermic peak is observed at $\sim 550^{\circ} \mathrm{C}$, which corresponds to the transformation of kaolinite into metakaolin $\left(\mathrm{Al}_{2} \mathrm{O}_{3} \cdot 2 \mathrm{SiO}_{2}\right) .{ }^{18}$ A second endothermic peak is evident within the temperature range of $700-850^{\circ} \mathrm{C}$, together with the corresponding loss of the weight, which is attributed to the dehydroxylation of talc. Dilatometric studies ${ }^{17}$ revealed that shrinkage begins at $\sim 850^{\circ} \mathrm{C}$. At $\sim 950^{\circ} \mathrm{C}$ 
(a)

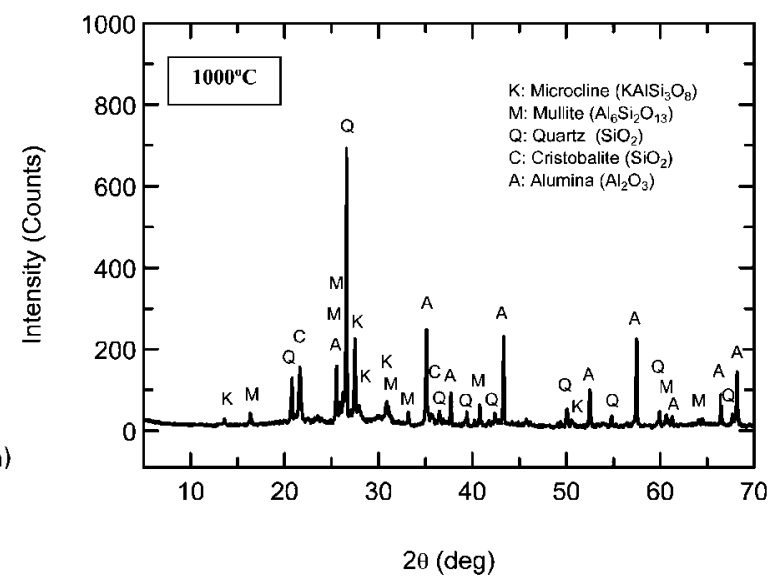

(b)

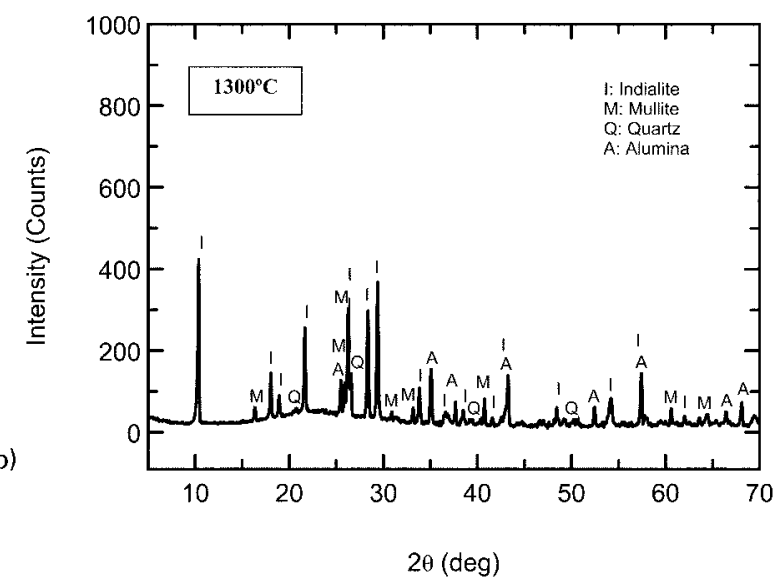

a $1000^{\circ} \mathrm{C} ;$ b $1300^{\circ} \mathrm{C}$

6 X-ray diffraction patterns obtained after sintering raw material at different temperatures for $1 \mathrm{~h}$

an endothermic peak is observed, which corresponds to the transformation of metakaolin into a spinel type structure together with amorphous silica. ${ }^{18}$ As the temperature rises, porosity decreases via viscous phase sintering and the rates of formations of both mullite and cordierite increase, although this process is too slow to be detected by DTA. However, at $1000^{\circ} \mathrm{C}$, the presence of mullite is clearly identified by XRD analysis, as patent in the XRD pattern in Fig. 6 (top). Above $1250^{\circ} \mathrm{C}$, a small exothermic peak is observed in the DTA curve, which reveals the rapid formation of cordierite. The influence of the mullite's availability on the formation of cordierite is not proved, but it is evident that the bars sintered at $1300^{\circ} \mathrm{C}$ for $1 \mathrm{~h}$ contained both cordierite (identified as indialite, the synthetic cordierite phase stable at high temperatures) and mullite, together with unreacted alumina and quartz, as shown in the XRD pattern in Fig. 6 (bottom).

\section{Discussion}

\section{Structural relations between 'replicated' CF and their PU template}

As already mentioned, the selection of the template is crucial in determining the ceramic cell and window size distributions. Indeed, cordierite based foams reflect the polymeric structure, with alterations that result from both the physicochemical reactions associated with the fabrication process adopted and the processing parameters selected. The key processing parameters, such as the composition and the rheological behaviour of the ceramic slurries, which do affect the final structure, are out of the scope of the present work. As observed in Table 1 and Fig. 3 the ceramic foams, when compared with their polymeric templates, present the following main differences: (1) higher number of closed windows; (2) smoother cells, approaching the spherical shape; (3) smaller mean cell size (Table 1) and narrower cell size distributions (Fig.3); (4) larger mean window size (Table 1) and narrower window size distributions (Fig.3). These differences are related with the 'replication' process, which promotes the smoothing and 'rounding' of the ceramic cells shape, under the pressure of the gases liberated by the polymer burnout and the shrinkage of the ceramic material, upon sintering. It is postulated that the burnout of the polymeric template causes the dilation of the windows, as shown in Fig. 3. Moreover, the sintering is governed by the classic mechanisms in the presence of a liquid phase, namely rearrangement, diffusion, creep and viscous flow of the ceramic particles. The shrinkage associated with sintering mechanisms is responsible for the disappearing of the smaller pores (in the range of $50-250 \mu \mathrm{m}$ ), and occurs in a degree proportional to the pore size, i.e. $29 \%$ for $\mathrm{CF}(20 \mathrm{DB})$ and $32 \%$ for $\mathrm{CF}(22 \mathrm{SB} 4)$. These values were determined from measurements of the solid volume fraction, before and after sintering.

Experimental evidence also suggests that the presence of closed cell windows contributes to the overall shrinkage. In fact, the ceramic foam containing higher proportion of closed windows $\mathrm{CF}(22 \mathrm{SB} 4)$ did contract slightly more than the other one $\mathrm{CF}(20 \mathrm{DB})$. On the other hand, the solid volume fraction falls within the range of expected values, as determined from the data gathered for bulk density ( $\rho$ ranging from 0.49 to $\left.0.51 \mathrm{~g} \mathrm{~cm}^{3}\right)$ and true density of the solid struts $\left(\rho_{\mathrm{s}}=2.6 \mathrm{~g} \mathrm{~cm}^{-3}\right)$. The porosity of the developed foams, given by $P=1-\rho / \rho_{\mathrm{s}}$, is of the order of $80 \%$, i.e. slightly lower than that measured by optical microscopy. This is not surprising in view of the data ${ }^{13}$ that was associated with inherent difficulties in resolving the foam structures in depth by optical images, when compared with the electron ones.

Typical defects of ceramic foams manufactured by the replication method include voids inside the struts, which result from the polymer burnout, and cracks between the cell walls, result from the thermal expansion mismatch between the polymer and the ceramic powder coating, during the initial heating stage of the polymer pyrolysis. $^{12,19}$ These defects, illustrated in Fig. 7, are known to reduce significantly the mechanical properties of the material. ${ }^{20}$

\section{Tailoring replicated ceramic foams}

The burnout of the polymer template is associated with reactions which lead to weakening the structure: on the one hand, gases are generated which cause the formation of internal voids (Fig. 7) and, on the other hand, the shrinkage of the material, which occurs as the polymer is removed, gives rise to the appearing of cracks (Fig. 7). For this reason, an extremely low heating rate ought to be employed, in order to promote the uniform removal of the polymer and thus minimise the formation of cracks. However, the difference in the thermal expansion coefficient of the polymer substrate (about $100 \times$ $10^{-6} \mathrm{~K}^{-1}$ ) and the cordierite based coating 


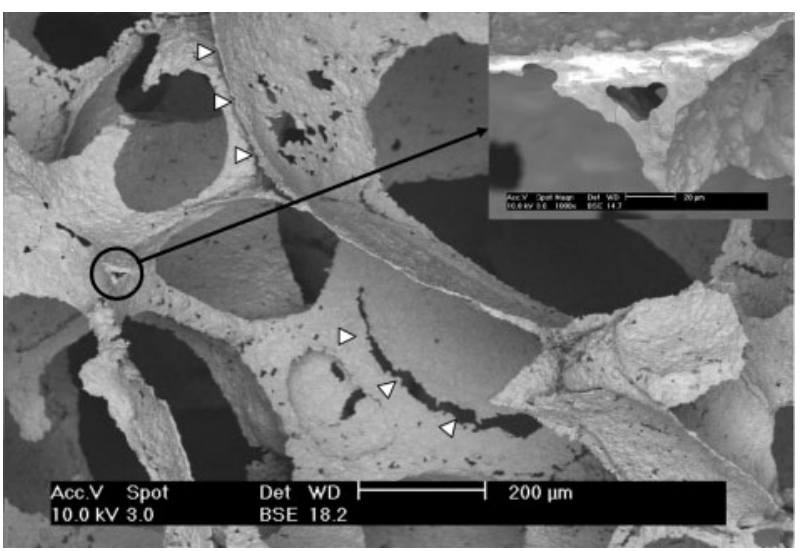

7 Typical defects observed in foams produced by replication method: hollow struts (indicated by circle) and cracks (indicated by arrows); at top right, hollow strut is shown in more detail

$\left(4 \times 10^{-6} \mathrm{~K}^{-1}\right)$ is regarded as a primary source of cracking. Moreover, the thermal expansion of the polyurethane is expected to increase as the temperature approaches its melting point. Therefore, proper control of the polymer burnout is essential to overcome cracking.

Under the thermal oxidative degradation conditions, decomposition products are generated throughout the body and diffuse to the surface, where evaporation takes place. The rate of this reaction is limited by the oxygen diffusion and is more pronounced at the surface. Mass transport processes (similar to those found in solvents drying from particle beds) are therefore thought to operate during the burnout of the polymer template. Particles are drawn together under the effect of the capillary forces that arise from the curvature of pores in the polymer, or from interparticle surface menisci, as in the case of the mechanism proposed for the initial rearrangement stage in liquid phase sintering.

Since the gases dilate much more than the solid material, gases generation builds up an internal pressure in particles packing. This phenomenon does not contribute to the densification process. However, as the gases diffuse away from the structure through the open porosity, the size of the pores do enlarge. Under the increase of the gaseous pressure, the cells, still soft and mouldable, become more 'spherical' (so that the solid surface area is minimised) and the cell window diameters dilate to allow the gases to escape, and 'round', owing to the referred 'spherical effect'.

Above $450^{\circ} \mathrm{C}$, the weight losses resulted mainly from dehydroxylation processes, involving the release of $\mathrm{OH}^{-}$ groups contained in the raw materials. The rate of the gases generation (mainly $\mathrm{H}_{2} \mathrm{O}$ and $\mathrm{CO}_{2}$ associated to the decomposition of the raw materials) is assumed to be extremely low, when compared to the produced at lower temperatures, and ought to have no further effect on the shape of the cells.

\section{Image analysis performance}

Structures would be ideally assessed by means of direct non-invasive techniques capable to perform internal 3D evaluations. Although this is not achievable by a unique technique, the imaging methods, namely the image analysis (IA), reveal aptitude to provide embracing useful information on complex structures.
Image analysis was used in the present study, proving to be an economical tool, enough to evaluate the internal structure of foams. In fact, the provided information, although being bidimensional (and/or unidimensional), concerns a high variety of parameters (chosen according to the required structural features, which in turn reflect specific properties) as well as an unlimited number of measurements.

The loss of information inherent to the planar data may be efficiently minimised either by adequate stereological procedures or by obtaining additional information, by means of 'complementary' analytical techniques. In addition, the possibility of acquiring and processing a high number of measurements (by automating the procedures) allows dealing with statistically representative data, which is a crucial factor in the field of modelling.

Concerning the 3D inference, no stereological procedure may be applied to the actual data. This is because, although obtained on random sections, the data was not collected from random measurements, but by measuring the cells with the 'circular' shape, containing 4 or 5 struts, under focus. Such procedure, as well as the volumic characteristic of the parameter chosen to describe the cell size (cell equatorial diameter), aimed at approaching the measured size (2D) to the real size (3D). The deviations that derive from the cells shape and preferred spatial orientation were overpassed by assuming the cells sphericity.

Concering the modelling of the structure, the data reported in this work, as well as the data available in the literature, are insufficient to allow deriving mathematical relations efficient in describing the macrostructural changes of the ceramic foams upon sintering, especially the relations between the pore size distribution and the total porosity. For this reason, an available theoretical model was tested for the aptitude of describing the structural relations observed in the 'replicated' cordierite-based foams.

\section{Model testing: relations between porosity and structural dimensions}

Peng et l. $^{21}$ derived a model for correlating the overall porosity with the structural dimensions of a single cell. This is given by the following mathematical expression

$$
V_{p}=\frac{\pi}{\sqrt{2}}\left[\frac{3}{1-k^{2}}-\frac{5}{3}\left(\frac{1}{\sqrt{1-k^{2}}}\right)^{3}-1\right]
$$

where $V p$ represents the porosity and $k=w / D$ represents the dimensional ratio between the window and the cell diameters.

The model is considered to apply to both foaming ceramic foams and commercially available high porosity ceramic foams, ${ }^{21}$ which led us to test it on our high porosity ceramic foams. Data from Table 1 were used in the expression being obtained the estimated porosities of $64 \%$ for foam $20 \mathrm{DB}(\mathrm{k} \sim 0.70$ and measured porosity of $75 \%)$ and $4.4 \%$ for foam $22 \mathrm{SB} 4(\mathrm{k} \sim 0.76$ and measured porosity of $70 \%$ ). Estimatives neither agree with the data measured, nor are coherent with the internal structures.

A detailed analysis of the model revealed the abnormal deviations, as is the case of ceramic foams with $k>0.76$ (available in the market), and indicated 
which porosity estimates the expression to be negative. This is a non sense estimate for real high porosity foams.

Although being high porosity, the model can not be applied to the actual structures because these do not meet the model assumptions: cells are 'coarse' instead of 'fine', distributed in wide size ranges (Fig. 3) instead of monosised and, additionally, some of them contain walls (Fig. 1) instead of being open.

In summary, it can be concluded that the model proposed by Peng et al., though having proved to be applicable to the foams produced by the foaming method, ${ }^{21}$ cannot be used to describe high porosity foams, in general. In practice the assumptions of the model can be applied to very specific real foams. Besides, the window diameters are strongly dependent upon the manufacturing method and do vary over a wide data range, even for foams with the same relative density.

\section{Conclusions}

The structures of replicated ceramic foams and the respective polymer templates are closely related. However, structural differences are observed, which furnish crucial information for tailoring 'replicated' cordierite based foams.

When compared with their PU counterparts, ceramic foams present smaller average cell diameters, distributed in a narrower size range. This is owing to the material shrinkage, which brings down the size of the cells, the finer ones tending to disappear. Ceramic foams also present larger average window major axis, distributed in a narrower size range. The dilation of the windows results from the establishment of the pressure inside the cells, owing to the gases generation, associated with the polymer degradation. The narrower size distribution issues from the shrinkage of the material, as referred above.

Actual research is to be prosecuted in advancing from the actual qualitative information to establishing quantitative relationships between cordierite based foams and their polymeric template structures. Understanding and quantifying the structural relations, as well as the processes involved, is the first step in the 'tailoring challenge'. The second is to conduct the tailoring process as embodied in an enlarged industrial materials scope in which materials are produced to make objects and the objects are created to perform predesigned functions.

In a full context, tailoring a ceramic foam is to be faced attending to the objects to be fabricated and to the multiple interplays of the object function, shape, fabrication method and material.

\section{Acknowledgements}

The authors gratefully acknowledge the financial support of the 'Fundação para a Ciência e a Tecnologia' (FCT) under contract POCTI/CTM/35470/00. Special thanks are extended to A. T. Crujeira from the Department of Energy Engineering and Environmental Control of INETI (polymer burnout exhaust gases analyses), as well as D. Dias from Rauschert Portuguesa Ltd and A. Moreira from Flexipol Espumas Sintéticas, S. A. for supplying the raw materials and the PU foams, respectively.

\section{References}

1. P. Colombo: 'Key engineering materials', Vols. 206-213, 19131918; 2002, Switzerland, Trans. Tech. Publications.

2. L. B. Younis and R. Viskanta: Int. J. Heat Mass Transfer, 1993, 36, 1425-1434.

3. F. A. Acosta, A. H. Castillejos E., J. M. Almanza and A. Flores: Metall. Mater. Trans. B, 1995, 26B, 159-171.

4. R. Brezny and D. J. Green: J. Am. Ceram. Soc., 1993, 76, 21852192.

5. R. Brezny and D. J. Green: J. Am. Ceram. Soc., 1989, 72, 11451152 .

6. E. E. Underwood: 'Quantitative stereology'; 1970, Reading, MA, Addison-Wesley.

7. 'Standard test method for cell size of rigid cellular plastics', D357698, American Society for Testing and Materials, West Conshohocken, PA, USA, 1999.

8. O. B. Olurin, M. Arnold, C. Körner and R. F. Singer: Mater. Sci. Eng. A, 2002, A328, 334-343.

9. E. Maire, P. Colombo, J. Adrien, L. Babout and L. Biasetto: J. Eur. Ceram. Soc., 2006, in press.

10. S. Mullens, J. Luyten and J. Zeschky: 'Cellular ceramics: Structure, manufacturing, properties and applications', 227-266; 2005, Weinheim, Wiley-VCH Verlag GmbH \& Co.

11. K. Schwartzwalder and A. V. Somers: US Patent 3090 094, 1963.

12. F. A. Costa Oliveira, S. Dias, J. Mascarenhas, J. M. F. Ferreira, S. Olhero and D. Dias: in 'Materials science forum II', (ed. R. Martins et al.), Vols. 455-456, 177-181; 2004, Switzerland, Trans. Tech. Publications.

13. M. J. Matos, M. F. Vaz, J. Cruz Fernandes and F. A. Costa Oliveira: 'Materials science forum II', (ed. R. Martins et al.), Vols. 455-456, 163-167; 2004, Switzerland, Trans. Tech. Publications.

14. M. J. Matos, R. Lastra and W. Petruk: Trans IMM, 1996, 105, C133-140.

15. H. X. Peng, Z. Fan and J. R. J. Evans: Ceram. Int., 2000, 26, 887895.

16. J. M. Tulliani, L. Montanaro, T. J. Bell and M. V. Swain: J. Am. Ceram. Soc., 1999, 82, 961-968.

17. F. A. Costa Oliveira, N. Shohoji, J. Cruz Fernandes and L. Guerra Rosa: Solar Energy, 2005, 78, 351-361.

18. W. M. Carty and U. Senapati: J. Am. Ceram. Soc., 1998, 81, 3-20.

19. D. D. Brown and D. J. Green: J. Am. Ceram. Soc., 1994, 77, 14671472 .

20. F. A. Costa Oliveira, S. Dias, M. F. Vaz and J. Cruz Fernandes: J. Eur. Ceram. Soc., 2006, 26, 179-186.

21. H. X. Peng, Z. Fan, J. R. G. Evans and J. J. C. Busfield: J. Eur. Ceram. Soc., 2000, 20, 807-813. 